\title{
The typology of syncretisms and the status of feature structure. Verbal paradigms across 355 Dutch dialects
}

\author{
Suzanne Pauline Aalberse
}

Received: 05 April 2006/Accepted: 13 April 2007/Published online: 29 August 2007

(C) Springer Science+Business Media B.V. 2007

\begin{abstract}
In this article syncretic patterning in the present indicative paradigm of the verb kloppen ('to knock') is described for 355 Dutch dialects taken from the morphological atlas of Dutch dialects (Van den Berg 2003). Following Baerman et al. (2005, The syntax-morphology interface. A study of syncretism. Cambridge: Cambridge University Press), I distinguish syncretisms driven by (universal) feature structure and language specific sources of syncretism. I present independent evidence for the role of phonology, pragmatics and amplification in the formation of syncretic patterns of Dutch. The benefit of the study of the interaction between language specific routes to syncretism and feature structure is threefold. We know language specific routes to syncretism can obscure feature structure. By distinguishing the different routes to syncretism we can also reveal the strength of feature structure. Secondly, distinguishing sources of syncretisms enables us to understand similarities and differences in the cross-linguistic patterning of syncretisms. Thirdly, we can link typological data to language acquisition patterns.
\end{abstract}

Keywords Syncretism - Verbal inflection · Feature hierarchy · Amplification · Dialectal variation

\section{Introduction}

In the Dutch dialect of Kampen the paradigm of the present indicative consists of three suffixes: Schwa marks first person, $-t$ marks third person and all plural forms and second person singular are marked by -en. The verbal

\footnotetext{
S. P. Aalberse ( $\square)$

Faculty of Arts, Department of Dutch Linguistics,

University of Amsterdam, Spuistraat 134, 1012 VB

Amsterdam, The Netherlands

e-mail: s.p.aalberse@uva.nl
} 
paradigm of Kampen as presented in (1) is in line with the interpretation of the dialect by Bennis and Maclean (2007) who interpret the formal overlap between the plural forms and second person singular as morphologically systematic. The point of departure in their work is that there is a one-to-one relationship between meaning and form. I refer to the approach of Bennis and Maclean (2007) as the economy approach.

(1) Present indicative of Kampen: the economy-approach

\begin{tabular}{lll}
\hline & Singular & Plural \\
& & \\
1 & $-e$ & $-e n$ \\
2 & $-e n$ & $-e n$ \\
3 & $-t$ & $-e n$ \\
\hline
\end{tabular}

De Vogelaer (2005) on the other hand relates the homophony between second person singular and the plural forms in the dialect of Kampen to morphologyexternal factors, namely phonology and the introduction of new pronouns. The paradigm in (2) reflects the approach of De Vogelaer (2005) in which all homophony is accidental. I refer to the approach by De Vogelaer (2005) as the traditional approach. ${ }^{1}$

(2) Present indicative of Kampen: the traditional approach

\begin{tabular}{|c|c|c|}
\hline & Singular & Plural \\
\hline 1 & $-\varnothing$ & -en \\
\hline 2 & -en & -en \\
\hline 3 & $-t$ & -en \\
\hline
\end{tabular}

Theoretically the account of Bennis and Maclean (2007) is attractive because it is parsimonious and because it has predictive power. Bennis and Maclean (2007) formulate generalizations that hold for all Dutch dialects. Since syncretisms are accidental in the traditional approach, no predictions on possible or impossible syncretisms follow from it. The empirical evidence for the role of external factors in the creation of syncretisms as presented by De Vogelaer (2005), however, is in most cases convincing. De Vogelaer (2005) for example shows that the suffix -en in the singular is the result of a polite strategy that motivated the use of second person plural pronouns and inflection as a form of address towards one addressee.

\footnotetext{
${ }^{1}$ De Vogelaer (2005: 93) does not deny the possibility that morphology internal factors can also influence the formation of syncretisms in some languages, but he claims that Dutch inflectional markers are 'inert and dead'. De Vogelaer relates the inert condition of Dutch inflection to the fact that Dutch is an obligatory agreement language.
} 
The suffix -en only marks second person singular in combination with the pronoun $j i j$, a pronoun that was originally a second person plural marker. It is clear from the work of De Vogelaer (2005) that non-morphological factors can affect the appearance of a verbal paradigm. The implicit denial of the role of these nonmorphological factors in the description of syncretisms in the economy approach may result in the formulation of debatable morphological generalizations.

An example of a morphological generalization that is debatable is the collapse of second person singular and all plural forms under one header in the paradigm in (1). In contrast to the neutralization of person features in the plural, the formal overlap between second person singular and second person plural is cross-linguistically rare (cf. Aikhenvald and Dixon, 1998: 66; Baerman et al. 2005: 59; 220; Hickey, 2003: 346). Baerman et al. (2005: 169-170) relate tendencies in the cross-linguistic patterning of syncretisms to different diachronic routes to syncretism. They claim that feature structure is responsible for universal tendencies and language specific alternations can be related to sources of syncretism outside feature structure. One source of syncretism outside morphology is politeness. Politeness strategies motivated the use of second person plural marking in the singular.

By distinguishing syncretisms driven by feature structure and syncretisms driven by sources outside feature structure Baerman et al. (2005) unite the strengths of the economy approach and the traditional approach. They are able to formulate generalizations in syncretic patterning and they acknowledge the role of non-morphological factors in the formation of syncretism. At first sight however allowing different forms of explanation in a theory might make it difficult to falsify that theory. In this article I describe various sources of syncretisms, and I formulate forms of independent evidence for each source of syncretism. Sections 2-4 are general sections. First, I describe universal tendencies in syncretic patterning. In Sect. 3, I present possible origins of these universal patterning in syncretisms, and in Sect. 4, I discuss potential sources for alternations from universal tendencies. Sections 5 and 6 focus on syncretic patterning in the present indicative of the verb kloppen ('to knock') in 355 Dutch dialects taken from the Morphological Atlas of Dutch dialects (Van den Berg 2003). ${ }^{2}$ In Sect. 5 the sources of syncretism discussed in Sects. 3 and 4 are related to the Dutch situation. Section 6 is an overview of syncretic patterning in the Dutch dialects. The conclusion of this overview is that in most cases the effects of different sources of syncretism coincide. There are however some syncretisms that are not in accordance with universal tendencies and these syncretisms have a verifiable source outside feature structure. More interestingly, we also see that in many dialects non-feature-structure-driven syncretism are replaced with a syncretism that is in accordance with feature structure: Two thirds of the Dutch dialects that had syncretism between second person singular and plural lost this

\footnotetext{
2 The Morphological Atlas of Dutch dialects consists of 613 measure points of Dutch and Frisian dialects in the Netherlands, Flanders and France gathered between 1980 and 1995. Each measuring point is taken to represent a dialect. For this article I coded and analyzed the present indicative of the verb kloppen for the Dutch dialects in the Netherlands (355 dialects). More information on the Morphological atlas and its methodology is available at http://www.meertens.knaw.nl/projecten/ mand and in Goeman and Taeldeman (1996).
} 
syncretism again in favour of a consistent distinction between the singular and the plural forms. The former syncretism was created via a language specific route; the new syncretism between all plural forms was created solely via feature structure. In a sense we could say that the creation of a syncretism between second person singular and second person plural via language specific routes obscured feature structure. But at the same time the loss of this language specific syncretism in favour of a cross-linguistic frequent pattern reveals the strength of feature structure. Section 7 concludes the article with a discussion of the advantages of systematically distinguishing different sources of syncretism.

\section{Universal tendencies in verbal inflection}

Cross-linguistic comparison of verbal inflection reveals certain universal tendencies. In this section I give a brief overview of these universal tendencies. The first set of similarities between languages in the marking of verbal inflection concerns the selection of the features that are expressed inflectionally. Bybee (1985: 204-205) shows that if a language has verbal inflectional morphology, it is likely to express the feature number and considerably less likely to express gender. No language expresses temperature or interestingness inflectionally (cf. Pinker 1996: 168). The subdivisions made in the specification of inflectional features also show cross-linguistic similarity. There is no language that divides the category tense into a category [+present] and [-present] in the sense that the past tense and the future tense share one form that is different from the present tense (Aikhenvald and Dixon 1998: 58). If a language has two categories of tense, it consists of either [+past] [-past] or [+future] [-future]. If a language has two levels of number marking, then it always distinguishes between the singular and the plural and never between [+dual] [-dual]; that is that the singular and the plural are grouped together and the dual is marked distinctively. Moreover, no language marks the distinction $[\leq 2]$ versus $[>2]$ in the sense that the singular and the dual are grouped together as opposed to plurals that consist of more than two items. In other words, the category [dual] depends on the availability of the distinction between the singular and the plural. These generalizations only hold if we consider language as a whole. In order to mark the dual, a language needs to mark the plural and the singular separately in some paradigms though not necessarily in all paradigms. Baerman et al. (2005: 93) cite Watkins (1984: 82-89) who shows that in Kiowa there is a word class where singulars and duals group together whereas the plural is marked. Kiowa also has a word class where the singular and the plural group together and where the dual is separately marked. The crucial point is that Kiowa does mark the singular and the plural separately in some paradigms and this makes the appearance of dual marking possible. A less tidy cross-linguistic generalization concerns person marking. If person is marked inflectionally, this usually implies at least a three-way distinction between the speaker, the addressee and non-speech act participants. If only two persons are distinguished, this usually means that either first and second person group together or that second and third person share one form. A syncretism between first and third person is crosslinguistically rare (Baerman et al. 2005: 59). 
Apart from universal tendencies in the selection of feature marking, the fact that syncretisms exist is also a universal tendency. Baerman (2005: 808) and Baerman and Brown (2005a: 122, b: 118) show that syncretism-the use of one form to express multiple morphosyntactic functions-is pervasive in languages with inflectional morphology. Their language sample, for example, shows that in roughly two-fifths (60 out of a 140) of the languages investigated, subject person marking alone is neutralized in some contexts.

The third group of universal tendencies concerns patterning in syncretisms. The likeliness for a feature to be neutralized correlates with cross-linguistic frequency. A feature that is cross-linguistically less frequently expressed inflectionally such as gender is more likely to be neutralized than a relatively common inflectionally expressed feature such as number (Pinker 1996: 204-205). The most likely context for neutralization is the marked value of a dimension. The nonsingular for example is considered marked as opposed to the singular. If number is a neutralizing context in a language, it is almost always in the non-singular numbers. (Aikhenvald and Dixon 1998: 66; Baerman et al. 2005: 59, 220). To illustrate the notions of frequently neutralized features and frequently neutralizing context, let us compare paradigms in (3)-(5). In paradigm (3) we see the most common scenario: the not-so-frequently inflectionally expressed feature gender is neutralized in the marked number value plural. The scenario in (4) does not accord with the universal tendencies described in this section because a frequently inflectionally expressed feature [number] is neutralized in the context of a not so frequently inflectionally expressed feature [gender]. The paradigm in (5) does not accord with the observation that it is the unmarked values of a feature that form a neutralizing context. We expect neutralization in the non-singulars and here we see neutralization in the singular.

(3) Common: gender neutralized in non-singular

\begin{tabular}{lll} 
& Singular & Plural \\
Gender 1 & A & \\
Gender 2 & B & D \\
Gender 3 & C & D \\
& & D \\
\hline
\end{tabular}

(4) Uncommon: number marking depends on gender

\begin{tabular}{lll} 
& \multicolumn{1}{c}{ Singular } & Plural \\
\cline { 3 - 3 } Gender 1 & A & A \\
Gender 2 & B & E \\
Gender 3 & C & F \\
\hline
\end{tabular}


(5) Uncommon: neutralization in the singular

\begin{tabular}{lll}
\multicolumn{1}{c}{} & \multicolumn{1}{c}{ Singular } & \\
Gender 1 & A & \\
Gender 2 & A & D \\
Gender 3 & A & E \\
\cline { 2 - 3 } & & F \\
\hline
\end{tabular}

Although the patterns in (4) and (5) are rare, they probably do exist. Cysouw (2003) and Baerman et al. (2005) show that the possible variation in the patterning of syncretisms is immense. The uncommon paradigms in (4) and (5) still obey a bi-unique relation between one form and one meaning. This biunique relation between meaning and form is the most common relation in inflectional morphology, but again we see exceptions. In Middle Dutch for example there is a syncretism between the third person singular and the second person plural form that clearly violates the one form one meaning preference. What does it mean to have a feature hierarchy when it can be violated? Before I answer that question, I will first look into the different potential sources for syncretisms in Sect. 3 as an explanation for both crosslinguistic tendencies and language specific deviations in inflectional marking and more specifically in the patterning of syncretisms.

\section{Sources of universal patterning}

In the last section we saw an overview of cross-linguistic tendencies in the marking of verbal inflection and syncretisms. The goal of this section is to give an overview of potential sources of cross-linguistic generalizations. In subsection 1 I discuss the full word origin of inflectional markers, and in subsection 2 I discuss learning strategies.

\subsection{The full word origin of inflectional markers}

Inflectional markers typically originate from the progressive reduction of full words (Anderson 2004: 14). The full word origin of inflectional markers can account for some of the universal tendencies in inflectional marking described in the last section. First of all the frequently observed bi-unique relation between form and meaning is in line with the full word origin of inflectional markers. The question now is what words are likely to develop into inflectional markers. Bybee (1985) convincingly argues that two elements predict the likelihood of the fusion of one word with another word. The first factor is relevance. The greater the relevance of a word to the meaning of a verb, the greater the likelihood of that word to become a verbal inflectional marker. 
Bybee (1985: 13) considers a meaning relevant to another meaning element 'if the semantic content of the first directly affects or modifies the semantic meaning of the second'. Tense, for example, is more directly relevant to the meaning of a verb than gender, and therefore, it is not strange that more languages express tense on verbs than gender. The second factor that affects the change from full word to inflectional marker is generality. Since inflectional markers are obligatorily expressed on all verbs, the meaning of the category must be general enough to relate to all verbs. The notion of motion, for example, is highly relevant to a small set of verbs, but because the notion is not generally applicable to verbs, motion words do not become inflectional markers.

In short, the full word origin of inflectional words can account for the one-to-one relationship between meaning and form in inflectional markers, and it can account for the cross-linguistic similarity in feature selection in inflectional markers.

\subsection{Acquisition Strategies}

A second possible source for the cross-linguistic similarity in the patterning of syncretisms is language acquisition (Anderson 2004: 14). The following section is an attempt to relate cross-linguistic observations on the patterning of syncretisms to the question of learnability. I suggest seven strategies that language users could use in order to acquire the most common inflectional paradigms with the least amount of effort, and I relate these strategies to cross-linguistic tendencies in inflectional marking.

\subsubsection{Acquisition strategy 1: No inflection unless forced}

The first acquisition strategy that reduces the learning effort of the learner is the basis assumption that her language is without inflectional marking. Inflection is only assumed to be present if there is positive evidence for such an assumption (cf. Pinker 1984). The paradigm is acquired incrementally. Every extension of the inflectional paradigm requires positive evidence.

\subsubsection{Acquisition strategy 2: Monovalent features}

If a learner has evidence for the presence of inflection in her language, she will categorize inflectional information on the basis of monovalent features only. The absence of negative features greatly reduces the possible amount of variation (Harley 1994: 485; Harley and Ritter 2002). In the monovalent system, the default interpretation remains unmarked, and marked features receive a positive value. Say a language uses the suffix $-o$ to mark the singular and the suffix -am to mark the plural, then no number information is linked to the singular suffix - $o$ and the plural suffix -am is linked to the feature [plural]. The observation that no language marks the distinction between [+present] 
versus [-present] in the sense that there is no language that groups together the past and the future tense in one category [-present] as opposed to the category [present] can be related to monovalent marking. Present tense is a default form; and therefore present tense always remains unmarked. One positive feature that unites the future and the past tense and that excludes the default form is pragmatically not useful, and therefore we do not attest the distinction $[+$ present $][-$ present $]$ in the world's languages.

\subsubsection{Acquisition strategy 3: One form one meaning}

Point of departure for the language learner is that one form expresses one meaning. The assumption of a bi-unique relation between meaning and form greatly reduces the amount of variation that the learner needs to hypothesize and it is in line with the cross-linguistic tendency to link one meaning to one form.

\subsubsection{Acquisition strategy 4: elevant features first}

If a learner recognizes that her language marks inflection, she will first hypothesize that inflection is linked to a relevant category (in the sense of Bybee 1985). Only when relevant features cannot explain the attested form variation, less relevant features are hypothesized to affect inflection. This strategy is in line with the cross-linguistically frequent expression of relevant features.

\subsubsection{Acquisition strategy 5: General values first}

One of the cross-linguistic observations we saw in Sect. 2 was that the appearance of one feature value depends on the appearance of another value of that same feature. Duals do not show up in languages that do not also mark plurals. Harley and Ritter (2002) relate this observation to a conceptual feature hierarchy in which specific features such as duals depend on more general features such as a plural. The reason why every language that has a dual also has a plural is because the notion [dual] is conceptually dependent on the general notion [plural].

\subsubsection{Acquisition strategy 6: Relevant singles}

The relevant singles strategy means that if a meaning consists of two or more marked components, only the most relevant meaning (relevant in the sense of Bybee 1985) needs to be expressed. The relevant singles hypothesis explains why a feature like [gender] or [person] is less frequently expressed in the non-singular than in the singular. Since the singular is a default form, it has no number marking. If we want to express, for example, feminine gender in the plural, we need a number feature [plural] and a gender feature [fem]. The relevant singles hypothesis instructs the learner to express only the most relevant feature, in this case the plural. If the attested form variation in the input is 
not in accordance with the relevant singles hypothesis, the learner expands her options and will allow the expression of two marked features. If the expression of two marked features still does not do justice to form variation in the input, the learner expands her options again until justice is done to the input.

\subsubsection{Acquisition strategy 7: Full categories}

In order to further reduce the possible amount of variation, a language learner links a new feature to the full category. So if a learner acquires the feature [plural], plurality will be expressed every time a plural meaning is intended, unless the 'relevant singles principle' prevents it. If plurality is expressed in combination with the marked (and more relevant) tense feature [past] for example, the more relevant feature [past] might block the expression of plurality. An example of a violation from the full-category principle comes from English. In English no number is marked on second person. The pronoun you refers both to the singular and the plural. Hickey (2003: 346) shows that the absence of number marking merely on second person is cross-linguistically extremely rare. Moreover, most non-standard variants of English have regained a number distinction in second person such as y'all (<you all) you guys; youse; yez, and you'uns (Hickey 2003: 349-351; Wales 2004). ${ }^{3}$

\subsection{Summary}

In short we have seen two potential sources for cross-linguistic similarity in feature marking in verbal inflection and syncretisms; the full word origin of inflectional markers and language acquisition strategies. The full word origin of inflectional markers and the 'one-form-one-meaning-strategy' in language acquisition can account for the one-to-one relationship between meaning and form in inflectional markers. The cross-linguistic similarity in feature selection in inflectional markers can be related to the full word

\footnotetext{
${ }^{3}$ One of the anonymous reviewers notes that the absence of number marking does occur frequently in third person and (s) he substantiates this claim with a reference to Cysouw (2003). In his discussion of number neutralization (horizontal homophony in Cysouw's terms) Cysouw distinguishes two groups of languages; languages without an inclusive/exclusive distinction and languages with a distinction between inclusive and exclusive marking. The group of languages that mark an inclusive/exclusive distinction and that neutralize number in the context of third person are referred to as the Tupí Guaraní-type paradigm (Cysouw 2003: 143-145), languages without inclusive/exclusive marking and with neutralization of number in the context of third person are referred to as the Sinhalese-type paradigm (Cysouw 2003: 108-110). In both groups of languages that neutralize number on third person only, third person is mostly expressed via a demonstrative. First and second person are expressed via pronouns (Cysouw 2003: 108, 143-144). Since third person does not belong to the same category as first and second person, these cases do not form a counter example to the 'full-category-principle'. Cysouw (2003) also describes a few languages where first, second and third person do form one category and where number is neutralized in the context of third person. This homophony is not in accordance with the full category principle. The prediction is that there is motivation outside feature structure for number neutralization in these cases. Cysouw (2003: 301) further notes that examples with only partial dual marking in the paradigm are infrequent; 'In general there is a dual for all persons, or there is no dual at all'.
} 
stage of inflectional markers and to the 'relevant-features-first-strategy' in language acquisition. The 'monovalent-features-strategy' can explain why there is no language that distinguishes [+present] from [-present], 'the general values first-strategy' can explain why the occurrence of a dual depends on the availability of a plural. The 'relevant-singles-hypothesis' explains why features like person are gender or frequently neutralized in non-singular contexts. Lastly, the 'full-category-principle' can explain why the partial absence of the expression of plurality such as in English you is cross-linguistically rare.

\section{Routes to language specific patterning in verbal inflection}

In the previous section we looked into sources for universal patterning in syncretisms, but syncretisms can be highly language specific. In this section three routes to syncretism outside feature structure are discussed. The first route is a phonological one; the second route is related to amplification, and the third route concerns pragmatics.

\subsection{The phonological route}

Various types of phonological rules such as assimilation, deletion, vowel reduction and stress shift can affect the appearance of an inflectional paradigm. Our focus now is not on the specific technical details of these phonological operations but on the question how we can distinguish phonologically motivated neutralization patterns from morphologically motivated neutralization patterns. To capture the problem of distinguishing phonologically motivated syncretisms from morphologically motivated syncretisms, let us imagine the effects of a $-t$ deletion rule in the Dutch dialect of Eexterveen. The verbal inflectional paradigm of Eexterveen with $-t$ is presented in (6) and the hypothetical variant without $-t$ is presented in $(7)$.

(6) Eexterveen dialect without -t-deletion

\begin{tabular}{lll}
\hline & Singular & Plural \\
1 & $-\varnothing$ & $-t$ \\
2 & $-s t$ & $-t$ \\
3 & $-t$ & $-t$ \\
\hline
\end{tabular}


(7) Hypothetical: Eexterveen dialect with -t-deletion

\begin{tabular}{lll}
\hline & Singular & Plural \\
1 & $-\varnothing$ & $-\varnothing$ \\
2 & $-s$ & $-\varnothing$ \\
3 & $-\varnothing$ & $-\varnothing$ \\
\hline
\end{tabular}

If this -t-deletion scenario would apply in Eexterveen, how would we know that the syncretism between the plural form and first and third person singular is motivated by phonology and not by morphology? A possible indicator of the limited (or absent) role of morphology internal factors in the rise of this syncretism is the application of the sound change in circumstances where the rule does not yield morphological reorganization. An example of $-t$-deletion that does not yield morphological reorganization is - $t$-deletion in an uninflected noun such as rijst. The omission of $-t$ in rijs $(<$ rijst) is non-morphological. The omission of $-t$ in second person singular $(-s t \rightarrow-s)$ again is purely phonological since the omission does not change the abstract morphological pattern; second person remains uniquely marked. Since - $t$ deletion in the latter circumstances has no effect on the morphological level, but only on the phonological level, the rule must (partly) be rooted in phonology.

A second possible indicator for the role of phonology in - $t$-deletion is phonological conditioning. Goeman (1999: 472-473) shows that in many Dutch dialects, the occurrence of -t-deletion depends on the sonority level of the preceding and/or following sound among other factors. Low sonority of the sound that precedes and/or follows $-t$ leads to more $-t$-deletion. The complete scale of the level of sonority goes from loop $(t)$ (plosive, low sonority) $>$ zoch $(t)$ $($ fricative $)>\operatorname{kom}(t)>($ nasal) $>\operatorname{vaar}(t)$ (liquid) $>d u w(t)$ (glide) $>g a(a t)$ (vowel, high sonority). Because of the level of sonority, $-t$ is most likely to be deleted in verbs like loopt and least likely to be deleted in verbs like gaat. The effects of sonority relate directly to articulatory complexity and this is expected for phonological conditioning but unconnected to morphologically motivated alternations.

\subsection{The amplification route}

The label amplification with regard to morphology was introduced by Maiden (1992: 310). Maiden uses the term amplification for the analogical extension of phonologically conditioned allomorphy to verbs where such phonological conditioning is absent. Although we are now concerned with syncretisms and not with allomorphy, Maiden's observations are relevant to the formation of syncretisms. Maiden (1992) namely shows that language users are able to 
replicate semantically arbitrary patterns of form overlap and form differentiation that were originally thrown up by phonology into new domains where such phonological triggers are absent. If replication of form overlap and form differentiation is possible in stems, it should also be possible in inflection.

One of the examples Maiden (1992: 293) gives of allomorphy that is at first only phonologically conditioned is the palatalization of stem final velars in Italian triggered by a following /e/ or /i/. This phonological rules yields palatal consonants throughout the second and third conjugation, except for $1 \mathrm{SG}$ and the 3PL present indicative and for the 1SG, 2SG, 3SG and 3PL present subjunctive as shown in (8) for the verb leggere 'read'. Palatalization is not reflected in the spelling, but the phonetic version of the stem final consonant is added in every cell for the sake of clarity.

\begin{tabular}{|c|c|c|c|}
\hline Singular & Plural & Singular & Plural \\
\hline $\begin{array}{l}1 \text { leggo } \\
\text { /gg/ }\end{array}$ & $\begin{array}{l}\text { leggemo } \\
\text { /ddz/ }\end{array}$ & $\begin{array}{l}\text { legga } \\
\text { /gg/ }\end{array}$ & $\begin{array}{l}\text { leggiamo } \\
/ \mathrm{ddz} /\end{array}$ \\
\hline $2 \mid \begin{array}{l}\text { leggi } \\
/ \text { ddz } /\end{array}$ & $\begin{array}{l}\text { leggete } \\
/ \text { dd }_{3} /\end{array}$ & $\begin{array}{l}\text { legga } \\
\text { /gg/ }\end{array}$ & $\begin{array}{l}\text { leggiate } \\
/ \mathrm{dd}_{3} /\end{array}$ \\
\hline $3 \begin{array}{l}\text { legge } \\
/ \mathrm{dd}_{3} /\end{array}$ & $\begin{array}{l}\text { leggono } \\
\text { /gg/ }\end{array}$ & $\begin{array}{l}\text { legga } \\
\text { /gg/ }\end{array}$ & $\begin{array}{l}\text { leggano } \\
\text { /gg/ }\end{array}$ \\
\hline
\end{tabular}

The phonologically conditioned stem-alternation between /gg/ and / $/ \mathrm{dd}_{3} /$ in verbs that end in a velar consonant like leggere ('gg') was analogically extended to verbs that originally had a stem ending in a palatal consonant like fuggire ('dd'). Instead of the palatalization of the velars we thus get velarization of the palatal verb stems in all contexts except before /e/ and /i/, resulting in the same alternation pattern as in the verb leggere. Velarization occurs even though there is no phonological rule that changes palatals into velars. The extension of the phonological pattern is thus morphologically motivated.

\subsection{The pragmatic route}

In specific pragmatic conditions, number and/or person features can be neutralized to save the addressee's face (Brown and Levinson 1987; Head 1978; Heath 1991, 1998; Maiden 1992). A common politeness strategy is the use of second person plural forms as a reference to a singular addressee to express distance and respect. The plurality metaphor is most clearly recognizable on the pronoun but can also affect agreement. Comrie (1975) describes crosslinguistic differences in predicate agreement in the case of a politenessinduced plurality metaphor. The polite plural pronoun can trigger two types of agreement. The first type of agreement is agreement with the (superficially) plural pronoun; the second type of agreement is agreement with the 
(underlyingly) singular referent. His claim is that there is a noun-verb continuum-verb, participle, adjective, noun - and that the more verb-like a predicate is, the more likely it is to agree with the superficial (plural) pronoun and that more noun-like predicates agree with the underlying subject (singular). In Polish there is language internal variation in the kind of agreement politeness-induced plurals trigger as shown in (9). The examples in (9) are taken from Comrie (1975: 407).
a. Wy-ście byli (pl.) chorzy (pl.)
b. Wy-ście byli (pl.) chora (sg.)
c. *Wy-ście byla (sg.) chorzy (pl.)
d. Wy-ście byla (sg.) chora (sg.)
'You were ill'

The pronoun clitic combination $w y$-ście is always put in the plural in polite situations. In contrast with an underlyingly plural subject, politeness plurality can be combined with both singular and plural participles and adjectives. The participle byl-can be used in the singular as well as in the plural. Therefore the plural form byli and the singular form byla are both grammatical (compare (a) and (d)). The adjective chor- ('sick') can be used in the singular and in the plural, but the possibility to use the plural form chorzy depends on the expression of plurality on byl-. Examples (b) and (d) show that the singular form of chora is always correct. The plural form chorzy can only be expressed in the plural if byli is also put in the plural; therefore, example (a) is correct. Example (c) is out because absence of the plurality metaphor in the more verb-like participle implies absence of the plurality metaphor in the more noun-like adjective.

The generalization that holds for Polish also holds cross-linguistically; the presence of plural politeness agreement on the noun-like element implies politeness agreement on the more verb-like element in the language. When politeness triggers the use of a plural verb with a singular referent, we have pragmatically triggered number neutralization. An example of a language where pragmatically induced number neutralization is apparent on both the pronoun and the verb is present-day French. The singular informal tu aimes les syncretismes ('you like ${ }^{\mathrm{SG}}$ syncretisms') can be replaced by the plural vous

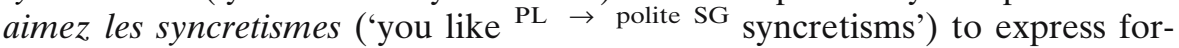
mality towards one addressee.

In the case of French we are dealing with a form of on-line substitution of one number value with another that does not affect the language system. But pragmatically motivated forms can end up being grammaticized to the point that the substitutions are the only ones in the paradigm and then what was originally motivated by pragmatics has become part of grammar (cf. Evans et al. 2000:209). This is exactly what happened in English. If we look at the paradigm of Southern Middle English in (10), we see the inflectional marker -st for the second person singular. This second person singular marker is lost in Modern English as shown in (11). English used to 
be like French in the sense that politeness triggered the use of both a plural pronoun and a plural verb. Thus the singular pronoun thou and the verbal inflection marker $-s t$ could be replaced by the plural pronoun ye/you and the verbal inflection marker $-\varnothing$ in formal situations. In English plural forms ended up replacing the second person singular all together thereby creating a syncretism between second person singular and second person plural as a systematic part of the English grammar. This type of number neutralization that is triggered by politeness strategies has entered the language via what I have coined the pragmatic route.

(10) Southern Middle English (cf. Lass 1999: 161)

\begin{tabular}{lll}
\hline & & \\
& Singular & Plural \\
1 & & \\
2 & (I) $-\varnothing$ & (we)- $\varnothing$ \\
3 & (thou) $-s t$ & (ye/you) $-\varnothing$ \\
& (he) $-s /-t h$ & (they) $-\varnothing$ \\
\hline
\end{tabular}

(11) Modern English

\begin{tabular}{lll}
\hline \multicolumn{1}{c}{ Singular } & Plural \\
& & \\
1 & (I) $-\varnothing$ & (we)- $\varnothing$ \\
2 & (ye/you)- & (ye/you) $-\varnothing$ \\
3 & (he) $-s /$-th & (they) $-\varnothing$ \\
\hline
\end{tabular}

\subsection{Summary}

In short we have seen three sources of syncretism outside feature structure, namely phonology, amplification and pragmatics. The sources of syncretisms outside feature structure are systematic within their own domain, for example, phonology or pragmatics, but they do not have to obey feature hierarchy and the language learner does not anticipate syncretisms that are not in accordance with feature structure. Non-feature-structure-driven syncretisms can be morphologically systematized as shown by Maiden (1992) but the occurrence of a non-morphologically motivated overlap in form is a pre-condition for amplification. The question now is to what extent non-feature-structure-driven syncretisms are relevant in the deflection process of Dutch dialects. Dialectal variation in deflection is the topic of Sect. 5. 


\section{Deflection routes in Dutch dialects}

In Sects. 3 and 4 we saw five potential sources for syncretism. The full word origin of inflectional markers and learning strategies are potential sources for universal tendencies. Phonology, amplification and pragmatics are possible factors in the motivation of cross-linguistic variation. The goal of this section is to give an overview of variation in the verbal deflection process of Dutch dialects and to relate the deflection process to the five sources of syncretism. In subsection 5.1, I will describe Middle Dutch variation in inflection. Middle Dutch is our point of departure in the description of dialect variation in Modern Dutch, and the central question is what factors motivated the change from Middle Dutch to Modern Dutch. In subsection 2, the five sources of syncretism are linked to specific predictions on the rise of syncretisms in Dutch. In subsection 3, the actual data are presented according to syncretism type. Attestations and explanations for the specific syncretisms are given.

\subsection{Middle Dutch variation}

In order to relate our five sources of syncretism to the deflection process of Dutch, we need to know what Middle Dutch verbal inflection looked like. There are three basic paradigms of Middle Dutch, presented in (12-14). Paradigm (12) is the Middle Dutch paradigm that is most commonly presented in historical grammars of Dutch (cf. Franck 1910; Van Gestel et al. 1992: 45), and it is based mainly on Southern Dutch texts. This paradigm already shows one instantiation of syncretism; third person singular and second person plural both combine with -(e)t. Paradigm (13) shows verbal inflection that occurred in some Eastern parts of the Netherlands. In this paradigm there is a syncretism between all plurals and the third person singular form that are all marked with -t. Goeman (1999: 228-230) also describes eastern Dutch areas where there is variation between -en and $-t$ as plural markers. Both -en and $-t$ can mark all plural forms and this variation is stable: the proportion of $-e n$ and $-t$ marking in the period $1300-1350$ is the same as the proportion -en and - $t$ marking in the following century. In the paradigm in (14) we see an inflectional variant that appeared mostly in the area of Groningen. In this variant all plurals and the infinitive are marked with -en (cf. Goeman 1999: 261).

(12) Middle Dutch I

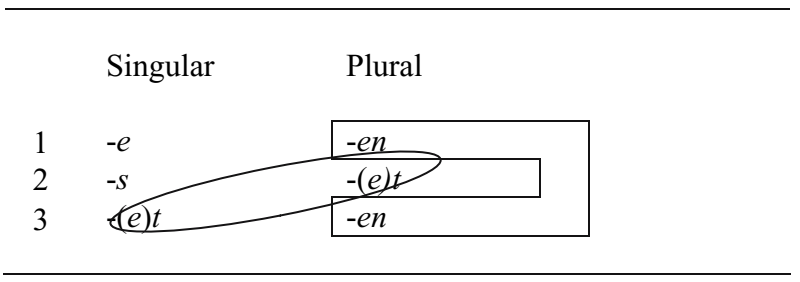


(13) Eastern Middle Dutch

\begin{tabular}{lll}
\hline & Singular & Plural \\
\cline { 3 - 3 } 1 & $-e$ & $-t /$ en $\&-t^{4}$ \\
2 & $-s$ & $-t /$ en $\&-t$ \\
3 & $-(e) \mathrm{t}$ & $-t /$-en $\&-t$ \\
\cline { 2 - 3 } & &
\end{tabular}

(14) Groningen Middle Dutch

\begin{tabular}{lll|}
\hline & Singular & Plural \\
& & \\
1 & $-e$ & $-e n$ \\
2 & $-s$ & $-e n$ \\
3 & $-(e) \mathrm{t}$ & $-e n$ \\
\hline
\end{tabular}

\subsection{The phonological route}

Phonological reduction rules that had the potential to affect the verbal paradigm in Middle Dutch are listed under (15). The rules listed are based on Goeman (1999: 1) and Weerman and De Wit (1999: 1177).

(15) Selection of phonological reduction rules in Middle Dutch
a. $n$-deletion (deletes $[n]$ at the end of words)
b. schwa deletion (deleted schwa at the end of words)
c. $t$-deletion (deletes $[t]$ at the end of words)

Application of the $-n$ deletion rule can result in a syncretism between first person singular, the infinitive and first and third person plural in Dutch which would then all be marked with the suffix $-e$. In Groningen $n$-deletion could result in a syncretism between first person, all plurals and the infinitive all of which would all be marked with $-e$. In Eastern Dutch full application of the $-n$ deletion rule yields a syncretism between first person singular and the infinitive, plus a partial overlap between first person singular, the infinitives and the $-e n \rightarrow-e$ variant of the plural.

Application of the schwa deletion rule has no effects on the abstract form of the paradigm. Because first person singular is the only feature set linked to this suffix, deletion of schwa will not yield a new syncretism in any of the three paradigms.

\footnotetext{
${ }^{4}$ I use the dash (/) to mark variation between dialects. The ' $\&$ ' sign marks variation within one dialect. In (13) this means that some Eastern dialects mark the plural with $-t$ only and that other Eastern dialects alternate between -(e)t and -en in the marking of the plural.
} 
Application of the $t$-deletion rule in the paradigm in (12) yields a syncretism between first and third person singular and second person plural that would all be marked with schwa. In the eastern paradigm in (13) it would yield a full syncretism between first and third person singular and with the originally $-e(t)$ variant of the plural. Since plurals can also be marked with -en, this is a partial syncretism only. In the Groningen paradigm as presented in (14) the application of the $-t$ deletion rule would yield a syncretism between first and third person singular, both of which would be marked with schwa.

\subsection{The amplification route}

The question is how amplification relates to dialectal variation in Dutch. Characteristic of the amplification route is that it concerns semantically arbitrary patterns of form overlap that were initially phonologically conditioned. The geographic distribution of syncretisms via the amplification route is highly constrained. In the central Italian dialects Maiden (1992) studied, the extension pattern always exactly replicates the local results of phonetically regular patterning (Maiden 1992: 299). Evidence for the amplification route thus comes from two sources: the abstract paradigm should have a phonological motivation (i), and the distribution of the paradigm should be confined to the area where there is evidence for phonological patterning of the abstract paradigm (ii). In the last section we saw that phonological factors can lead to a syncretism between first person singular and the first and third person plural, all marked with $-e$ as the result of an $-n$ deletion rule. If we see a syncretism between first person singular and first and third person plural marked to another form than $-e$, this could be due to amplification. This is only likely when the geographical distribution of the pattern first singular and first and third person plural is confined to an area where there is evidence for phonological conditioning of such a pattern.

\subsection{The pragmatic route}

The pragmatic route is also relevant in the deflection process of Dutch dialects. Like English, Dutch also used the second person plural pronoun and verb as a respectful form towards one addressee (Aalberse 2004; Vermaas 2002; Vor der Hake 1908). Like English the Standard dialects replaced the original second person singular pronoun $d u$ and the verbal inflection marker $-s(t)$ with the originally second person plural pronoun $g i j / j i j$ and the second person plural verbal inflectional marker -t. Again a syncretism between second person singular and second person plural came into existence via the pragmatic route. Because in Dutch politeness-induced number neutralization always affects the pronoun as well as the verbal inflectional marker the pronoun combines with, it is easy to recognize whether politeness has played a role in an inflectional paradigm. If the second person singular verb agrees with a cognate of the pronoun gij/jij we know the verb in the paradigm was originally plural. The pragmatic route can lead to two forms of syncretism. First 
there is neutralization of number features in second person. If we look at the paradigm in (12), we see that the second person plural combines with the same inflectional marker as the third person singular form. The use of the second person plural form in the singular thus also yields a syncretism between the second and the third person. In the Eastern dialects the replacement of the second person singular form by second person plural would yield a syncretism between all singular finite forms apart from first person singular. In the Groningen dialects the pragmatic route would only result in a syncretism between second person singular and second person plural.

\subsection{The full word origin $\rightarrow>$ The Middle Dutch origin}

The full word stage of inflectional markers can explain some cross-linguistic patterning, but it is not an explanation for deflection. More interesting in the study of deflection is the Middle Dutch origin of modern Dutch dialects. The classic Middle Dutch paradigm already shows a syncretism between the second person plural and the third person singular, which are both marked with -(e)t. If a dialect shows a syncretism between the second person plural and the third person singular, a likely source for the syncretism is conservatism.

\subsection{The acquisition route}

The point of departure in the acquisition route is a reduction of learning effort. The simplest paradigm in this perspective is a paradigm without inflection. The most extreme effect of the reduced effort strategy would be the absence of inflectional marking. If a learner does find evidence in her input that her language has inflection, she will begin by assuming the most relevant feature, which in the case of verbal inflection is finiteness. The simplest paradigm from an acquisition perspective solely marks the distinction between finite and non-finite forms. The full category principle requires that finiteness be marked on all finite forms.

If the learner finds that the distinction between finite and non-finite forms alone cannot justify the input, she will assume the second most relevant feature [tense]. After the hypothesization of finiteness marking and tense marking, the third option is number marking. It is possible that only finiteness and number are marked and that we find dialects without person marking. The fourth option is person marking. A likely step is the expression of person marking in the singular only because of the 'relevant singles hypothesis'. Instead of marking a three-way distinction between first, second and third person in the singular that we find in Middle Dutch, we would only see two persons marked. Since the combination of first and third person marking is cross-linguistically rare, we expect either a combination of first and second person singular or second and third person singular. The fifth option is a three- 
way person distinction in the singular. The most extensive route mirrors the input which implies the marking of a distinct second person plural marker if the point of departure for the paradigm was like (12).

\subsection{Summary}

In this subsection we linked the five deflection routes to syncretism to the Dutch situation. Three phonological reduction rules are relevant in the formation of syncretism in the Dutch situation: $-n$-deletion, schwa deletion and - $t$-deletion. The abstract patterning created via phonological reduction can spread via amplification. Evidence for amplification is formed by geographical distribution; only if the abstract paradigm replicates the local results of phonetically regular patterning is amplification a likely source for syncretism. Pragmatic rules can result in the neutralization of the number feature in the context of second person. Evidence for the pragmatic route can be derived from the pronoun; if the second person singular verb agrees with a cognate of the pronoun $g i j$, then we know we are dealing with an originally second person plural form. The most extreme result of the acquisition route would be the absence of inflectional marking. Less extreme results would be the absence of person marking, either in the plural or in the full paradigm. Another possible result is the reduction of the three-way person distinction to a two-way distinction in the singular, either between first and second person singular or between second and third person singular.

\section{Variation in verbal inflection in the present indicative in 355 Dutch dialects}

In this section I describe the syncretic patterns in the present indicative patterns of Dutch dialects attested in the Morphological Atlas of Dutch dialects (Van den Berg 2003) according to syncretism type. I list all instantiations of a syncretism and evaluate via what route the syncretism could have come into existence. Three of our 355 dialects mark all verbs with the inflectional marker -en. All three dialects are eastern dialects (F098p, M009p, G248p). Since these dialects express no number or person on the verb I have excluded them from the count. Let us now look at the syncretisms that appear in the 352 remaining dialects.

\subsection{Neutralization of person}

Table (16) shows that the neutralization of person features occurs frequently in the plural; 268 dialects out of a total of 352 neutralize person marking in the plural. There are 30 dialects without person marking in the singular. If a dialect does not mark person in the singular, it does not mark person in the 
plural either. Our observations on number marking are in accordance with our hypothesized acquisition strategies. The frequent neutralization of person in the plural can be related to the 'relevant singles hypothesis' that prevents the expression of a less relevant feature like person in combination with the marked value of a more relevant feature, in this case number. The absence of person marking in the full paradigm in 30 dialects can be related to step 2 in the configuration of an inflectional paradigm: mark only number and finiteness. Although the presence of number neutralization in the plural or full absence of person marking can both be related to acquisition strategies and thus to universal sources of syncretism, let us see whether language specific routes might also explain the loss of person marking by focussing on the actual attestations of the syncretism.

(16) Neutralization of person features in Dutch dialects

\begin{tabular}{|l|l|}
\hline & $1=2=3$ \\
\hline Singular & 30 \\
\hline Plural & 268 \\
\hline
\end{tabular}

$1 s=2 s=3 s$

If a Dutch dialect does not express person in the singular paradigm, all singulars are either expressed by $-\varnothing$ as shown in (17) or by $-t$ as shown in (18).

(17) $1 s=2 s=3 s$ : suffix $-\varnothing(24 \mathrm{x})$

\begin{tabular}{l|l|}
1 & $-\varnothing$ \\
2 & $-\varnothing$ \\
3 & $-\varnothing$ \\
\hline
\end{tabular}

(18) $1 s=2 s=3 s$ : suffix $-t(6 \mathrm{x})$

\begin{tabular}{l|l|}
1 & $-t$ \\
2 & $-t$ \\
3 & $-t$ \\
\hline
\end{tabular}


The appearance of zero in first and third person singular can be explained as the effect of phonological rules. Schwa deletion reduces $-e$ to $-\varnothing$ in first person singular and $-t$-deletion reduces $-t$ to $-\varnothing$ in third person. The story of second person is a little more complicated. Via the pragmatic route the second person plural suffix $-t$ takes over second person singular. Once the second person marker $s(t)$ is replaced by $-t$, the $-t$ - deletion rule gives $-\varnothing$ in second person singular. Thus we can explain absence of person marking linked to the suffix - $\varnothing$ not only in terms of the acquisition route but also in terms of a combination of language specific routes: phonological reduction and the pragmatically motivated extension of second person plural to second person singular. How can we understand the appearance of the -t-suffix as a marker for all singular persons? Here we have another case of amplification. The marking of $-t$ for all singular forms occurs only in Zuid-Holland, the province with the highest frequency of paradigms where all singular forms are marked with $-\varnothing$.

\section{$1 p=2 p=3 p$}

Let us now look at the 268 paradigms where person marking is absent in the plural. The feature plural is linked to the suffixes $-e(n)^{5},-t,-\varnothing,-t e$ as shown in $19-23$.

$1 p=2 p=3 p:$ suffix $-e(n)(211 \mathrm{x})$

\begin{tabular}{l|l|}
1 & $-e(n)$ \\
2 & $-e(n)$ \\
3 & $-e(n)$ \\
\hline
\end{tabular}

$$
1 p=2 p=3 p: \text { suffix }-t(39 \mathrm{x})
$$

\begin{tabular}{l|l|}
1 & $-t$ \\
2 & $-t$ \\
3 & $-t$ \\
\hline
\end{tabular}

\footnotetext{
${ }^{5}$ I have collapsed the suffixes $-e,-e n,-n$ and $-m$ in this count under the header $-e(n)$ because in most cases these suffixes are allomorphs. Some dialects distinguish $-e$ in the singular and -en in the plural. For such dialects where the alternation between $-e$ and $-e n$ is morphologically conditioned, the two suffixes $-e$ and $-e n$ are naturally not collapsed under one header.
} 
(21) $1 p=2 p=3 p$ : suffix $-e n \&-t(15 \mathrm{x})$

\begin{tabular}{l|l|}
1 & -en \& $-t$ \\
2 & $-e n \&-t$ \\
3 & $-e n \&-t$ \\
\hline
\end{tabular}

(22) $1 p=2 p=3 p$ : suffix $-\varnothing(2 \mathrm{x})$

\begin{tabular}{l|l|}
1 & $-\varnothing$ \\
2 & $-\varnothing$ \\
3 & $-\varnothing$ \\
\hline
\end{tabular}

(23) $1 p=2 p=3 p$ : suffix - te $(1 \mathrm{x})$

\begin{tabular}{ll|}
1 & te \\
2 & te \\
3 & te \\
\hline
\end{tabular}

In most cases the plural is marked by the suffix $-e(n)$ as shown in (19). In 39 cases the plural is marked with $-t$ as shown in (20). In 15 cases there is an alternation between $-t$ and $-e n$ in the plural as shown in (21). In two cases the plural is marked with $-\varnothing$ as shown in (22) and in one dialect the plural is marked with -te as shown in (23). The appearance of $-t$ as a plural suffix and the appearance of -en and $-t$ alternation can both be related to conservatism. Eastern Dutch dialects already marked all plurals either with only $-t$ or with $-t$ and -en in the fourteenth century as shown in (13). The appearance of zero marking in the plural can be related to a phonological rule, namely - $t$-deletion. The appearance of the suffix -te as a plural marker is mostly likely also related to -t-deletion. The $t$-deletion rule made it possible to reanalyze the alternation between $-\varnothing$ and $-t$ as fully phonologically conditioned. If the appearance of the -t-suffix becomes phonologically conditioned, the $-t$ in all singulars can be reinterpreted as part of the stem, resulting in plurals that end in -te.

The appearance of -en as a general plural suffix already occurred in Groningen in the 14th century. The massive spread of -en however cannot be ascribed to influence from Groningen. What then motivated the loss of $-t$ as a marker of second person plural? Van Aken (1996) claims that the introduction of a new second person plural pronoun jullie 
(>jij lui 'you people') is the source for a new suffix for second person plural. The plural marker lui 'people' in jullie has third person qualities and it is therefore natural that these third person characteristics trigger third person inflection. Goeman (1999: 251) and De Vogelaer (2005: 88-89 ) both show that there is no direct link between the appearance of the suffix -lie and plural suffixation. There are plural pronouns without -lie that combine with the suffix -en and there are pronouns with -lie that end in -t. Moreover, Buitenrust-Hettema (1891) shows that the appearance of $-e n$ as a marker for second person plural occurred gradually in Standard Dutch. The inflectional marker of the pronoun jullie passes through three stages as depicted in (20). In table (24) the label '+INV' stands for inversion of subject and finite verb, and '-INV' stands for all non-inverted orders. The inverted order is given as well because the inverted order can trigger agreement weakening (Ackema and Neeleman 2004: 194).

(24) Verbal inflection in combination with the pronoun jullie

\begin{tabular}{|l|l|l|l|}
\hline & Stage 1 & Stage 2 & Stage 3 \\
\hline- INV & $\begin{array}{l}\text { jij loopt } \\
\text { jullie loopt }\end{array}$ & $\begin{array}{l}\text { jij loopt } \\
\text { jullie loopt }\end{array}$ & $\begin{array}{l}\text { jij loopt } \\
\text { jullie lopen }\end{array}$ \\
\hline+ INV & $\begin{array}{l}\text { loopØ jij? } \\
\text { loopØ jullie? }\end{array}$ & $\begin{array}{l}\text { loopØ jij? } \\
\text { lopen jullie? }\end{array}$ & $\begin{array}{l}\text { loopØ jij? } \\
\text { lopen jullie? }\end{array}$ \\
\hline
\end{tabular}

In the first stage the pronoun jullie combines with exactly the same suffixes as the pronoun $j i j$. In the second stage the pronoun jullie combines with a suffix -en in the inverted order, the suffix that also marks first and third person plural. In the non-inverted order, however, second person singular and second person plural still form a syncretism. In the third stage jullie always combines with the marker -en, and the syncretism between second person singular and second person plural is cancelled out. There is now a general plural marker. The appearance of this plural marker cannot be related to language specific routes to syncretism. There must thus be another source, most likely language acquisition via the 'relevant singles first hypothesis'.

\subsection{Summary}

Although in line with feature structure, the absence of person marking can in almost all cases be related to language specific routes to syncretism. There is, however, one new syncretism that can only be related to feature structure, 
namely the appearance of a general plural marker -en at the expense of the original second person plural marker $-t$.

\subsection{Two-way person distinctions}

Cross-linguistically if a language only distinguishes two persons, that language groups first and second person together or second and third person together. First and third person rarely group together (Baerman et al. 2005: 59). If we look at the distribution of two-way person distinctions in the Dutch dialects, the syncretism between second and third person singular is extremely frequent; it appears 190 times in the singular. The syncretism between first and third person is pretty frequent in the plural; it appears 65 times as shown in (25).

(25) Two-way person distinctions in Dutch dialects

\begin{tabular}{|l|l|l|l|}
\hline & $1=2$ & $2=3$ & $1=3$ \\
\hline Singular & 17 & 190 & 22 \\
\hline Plural & 0 & 1 & 65 \\
\hline
\end{tabular}

$1 s=2 s \neq 3 s$

Homophony between first and second person singular is attested in 17 dialects. In most cases both first and second person are marked with $-\varnothing$ versus a $-t$ for third person. In one case first and second person are marked with $-e$ - and third person is again marked with $-t$.

(26) $1 s=2 s \neq 3 s$ : suffix $-\varnothing(16 \mathrm{x})$

\begin{tabular}{l|l|}
1 & $-\varnothing$ \\
2 & $-\varnothing$ \\
\hline 3 & $-t$
\end{tabular}

(27) $1 s=2 s \neq 3 s:$ suffix $-\varnothing(1 \mathrm{x})$

\begin{tabular}{l|l|}
1 & $-e$ \\
2 & $-e$ \\
3 & $-t$
\end{tabular}


The appearance of $-e$ for first person singular in paradigm (26) and the appearance of $-t$ for third person singular in paradigm and (27) can be related to conservatism. The appearance of $-e$ as a marker for second person singular in paradigm results from a combination of the pragmatic route and the phonological route. The pragmatic route brings the second person plural suffix -en into the singular and the $-n$ deletion rule changes $-e n$ into $-e$. The appearance of zero for first person in paradigm is related to schwa deletion. The origin of zero marking for second person singular is less clear. Depending on the form of the second person plural suffix, the pragmatic route either brings the suffix $-t$ or the suffix $-e(n)$ to the singular. A phonological rule can change the suffix $-t$ into $-\varnothing$. $-T$-deletion however, seems problematic as an explanation for the appearance of $-\varnothing$ in (26), because we still see a suffix $-t$ in third person singular. If we assume second person singular was originally marked with $-e$, schwa deletion alone cannot explain the zero for second person in (26), because ten dialects that mark second person singular with zero, mark the plural with schwa. The absence of a full explanation for the appearance of - $\varnothing$ as a marker for second person singular in (26) outside feature structure, suggests the role of feature structure.

Support for the hypothesis that the syncretism between first and second person is feature structure driven comes from the work of Harley and Ritter (2002) who claim that the syncretism between first and second person systematic whereas the syncretism between second and third person is not. Baerman et al. (2005: 59) and Cysouw (2005: 243), however, show that cross linguistically the syncretism between first and second person and between second and third person is almost equally common. The observations by Cysouw (2005: 243) and Baerman et al. (2005: 59) contradict the role of feature structure in the loss of $-t$ as a second person marker in the singular.

Another argument against the role of feature structure alone as an explanation for zero marking in first and second person is the observation that loss of $-t$ in second person is not systematic across all verbs in all dialects. If we look at the dialect of Groenekan (E193q) in the province of Utrecht, we see zero marking for second person (and not third person) in the verb kloppen. The verb doen ('to do') however combines with the inflectional marker $-t$ in second person. The discrepancy between the inflectional behaviour of the verb doen ('to do') and the verb kloppen ('to knock') can be related to phonological conditioning: The stem of the verb doen ('to do') is doe and ends in a vowel, whereas the stem of the verb kloppen, namely klop, ends in a plosive. In section 4.1 we saw that a low level of sonorancy of the preceding sound increases the chance of $-t$-deletion. It is therefore not strange that $-t$ is not deleted after the vowel in 'doe-" whereas it is deleted after 'klop-'.

The question now is why phonological conditioning distinguishes between second and third person. Goeman (1999: 187-189) relates the difference in behaviour of second and third person to the inflectional marker in the inverted word order. He shows that only dialects that have zero marking for second person in the inverted order, have a higher degree of $-t$-deletion in second person in the non-inverted order than in third person. Dialects that do not have zero marking in the inverted 
order in second person, like the Brabandish-Flemish dialects, do not differ in the rate of $-t$-deletion in second and third person in the non-inverted order.

$1 s \neq 2 \mathrm{~s}=3 \mathrm{~s}$

The syncretism between second and third person singular is very frequent in Dutch dialects. Both second and third person singular are most frequently marked with $-t$. In two instances both second and third person are marked with -Ø. In one instance second and third person are marked with -en.

(28) $1 s \neq 2 s=3 s:$ suffix $-t(187 \mathrm{x})$

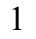

2

3

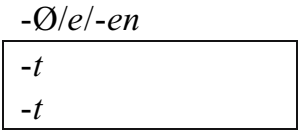

(29) $1 s \neq 2 s=3 s$ : suffix $-\varnothing(2 \mathrm{x})$

1

2

3

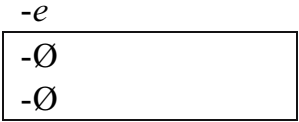

(30) $1 s \neq 2 s=3 s:$ suffix - en $(1 \mathrm{x})$

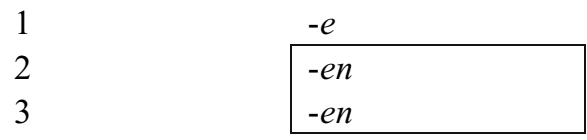

The appearance of $-t$ in third person singular inflection in paradigm (28) is the result of conservatism. Second person singular $-t$ always combines with a cognate of gij and is thus originally a plural form. The suffix $-t$ as a second person singular marker entered the paradigm via the pragmatic route that replaced second person singular forms by second person plural forms. The suffix $-t$ originally marked the second person plural. The paradigm in (29) is like the paradigm in (28) except for the fact that - $t$-deletion changed $-t$ in second and third person into $-\varnothing$. The appearance of -en as a suffix for second and third person marking is puzzling. The dialect in (30) is an Eastern dialect. 
In the Eastern dialects plurals are marked either only with $-t$ or with $-t$ and -en. The alternating suffix set $-t$ and $-e n$ may have entered the singular via the pragmatic route. Alternation between $-t$ and $-e n$ in the second person singular and all plural forms is indeed attested in Smilde in Drenthe as presented in (31). It is possible that our dialect in (30) was like the dialect in Smilde and developed into a dialect like (32) where the alternation between the suffixes $e n$ and $-t$ in the plural and in second person singular is extended to the full paradigm via amplification. Loss of the alternant $-t$ in paradigm (32) yields the paradigm in (30).

(31) Smilde

\begin{tabular}{lll|} 
& Singular & Plural \\
& & \\
1 & $-\varnothing /-e$ & $-e n /-t$ \\
2 & $-t /-e n$ & $-e n /-t$ \\
3 & $-t$ & $-e n /-t$ \\
\hline
\end{tabular}

(32) Extended -en/-t alternation into full paradigm

\begin{tabular}{lll|} 
& Singular & Plural \\
& & \\
1 & $-Ø /-e$ & $-e n /-t$ \\
2 & $-t /-e n$ & $-e n /-t$ \\
3 & $-(e) t$ & $-e n /-t$ \\
\cline { 2 - 3 } & &
\end{tabular}

If the appearance of -en as a marker for third person is the result of amplification, we predict that the suffix -en for third person is only observed in the region where -en and $-t$ are alternating suffixes. Map 1 shows that this is indeed the case. ${ }^{6}$

\section{$1 s=3 s \neq 2 s$ (first and third person singular are syncretic)}

If first and third person singular are homophonous they are always marked with zero. In nine cases second person is marked with $-s$ as shown in (34) and in 11 cases second person is marked with $-t$ as shown in (33). In the dialect of Wijk bij Duurstede (L001p) presented in (35) all three persons have zero marking, but only second person has vowel lengthening.

\footnotetext{
${ }^{6}$ Map 1 and 2 are the result of inserting kloeke-codes (special codes for all dialect measure points used in the phonological, the morphological and the syntactic atlas of Dutch dialects) in the drawmap function of DynaSand (Barbiers 2006). I am grateful to Alies Maclean for helping me with importing the maps into MSWord without information reduction.
} 


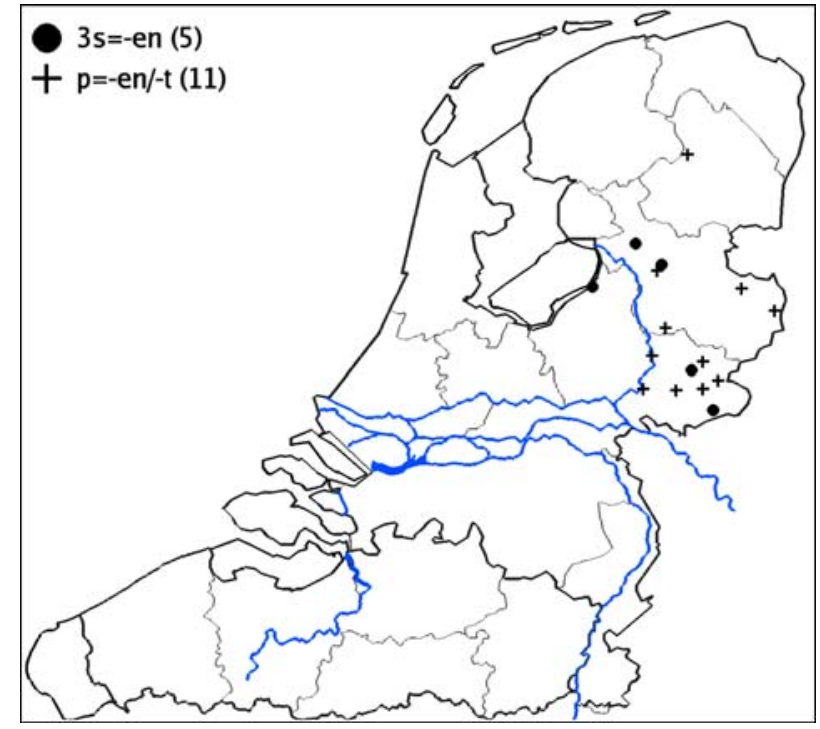

Map. 1 The geographical distribution of $\mathrm{p}=-e n /-t$ and $3 \mathrm{~s}=-e n$

(33) $1 s=3 s \neq 2 s$ : $-\varnothing$ versus $-t(12 \mathrm{x})$

\begin{tabular}{ll|}
1 & $-\varnothing$ \\
2 & $-t$ \\
3 & $-\varnothing$ \\
\hline
\end{tabular}

(34) $1 s=3 s \neq 2 s:-\varnothing$ versus $-s(9 \mathrm{x})$

1

2

3

\begin{tabular}{|l|}
\hline$-\varnothing$ \\
\hline$-S$ \\
\hline$-\varnothing$ \\
\hline
\end{tabular}

(35) $1 s=3 s \neq 2 s$ : klop versus kloop (1x)

\begin{tabular}{ll|}
1 & klop \\
2 & kloop \\
3 & klop \\
\hline
\end{tabular}


The zero for first and third person can be explained via the phonological route. Schwa deletion explains the $-\varnothing$ for first person and $-t$-deletion explains the zero for third person. The appearance of $-s$ for second person is a form of conservatism. If $-t$-deletion can account for the $-\varnothing$ in third person singular, how can we explain the presence of the marker $-t$ in the second person singular? The crucial part of the answer to this question is the fact that second person singular $-t$ originated in the plural and came into the singular via the pragmatic route. Goeman (1999: 310) shows that many dialects that delete $-t$ in the singular do not delete $-t$ in the plural. ${ }^{7}$ The reason why second person singular has not lost its $-t$ whereas third person has is because of the plural origin of second person singular. In paradigm (35) we see the dialect of Wijk bij Duurstede (L001p). All -t's are deleted in this dialect, but only second person shows vowel lengthening. The vowel lengthening in second person singular is a remnant of its second person plural origin. All plural verbs in the dialect of Wijk bij Duurstede show vowel lengthening. A further discussion on the dialect follows in the discussion of number neutralization in the context of second person.

$$
1 p=2 p \neq 3 p
$$

There are no syncretisms between first and second person only in the plural.

$$
1 p \neq 2 p=3 p
$$

There is one dialect in the Southwestern province of Zeeland where first person plural marking is unlike the marking of second and third person plural. The suffix -me marks first person plural and the suffix -en marks second and third person plural. The appearance of $-m e$ is an innovation. It is an extension of the suffix in the inverted word order.

\footnotetext{
${ }^{7}$ One reviewer asks if we can speak of a phonological rule when it is not applied blindly. - $T$-deletion in Dutch is always phonologically conditioned, an observation we cannot explain if the appearance of $-\varnothing$ would merely be morphologically conditioned. Goeman (1999: 310-311) shows that the likelihood of $t$-deletion correlates with the vowel length of the stem. Stems with a long vowel tend to retain the $t$-form longer than stems with a short vowel. It is this correlation between vowel length and the likelihood of -t-deletion that can explain the difference between singular and plural $-t$. Schwa syncope, in this specific case the reduction from the suffix -et to -t-triggered vowel shortening in the verb stem. Only after vowel shortening occurs, we see $-t$-deletion. So the development of the form [bli:vet] to [blif] consists of three stages: first syncope than, vowel shortening and then t-deletion. So: [bli:vet] $>$ [bli:ft] $>$ [blift] $>$ [blif] . Unlike the singular suffix $-e t$ the plural suffix - et is derived from the form -anth. Goeman (1999: 311) claims that the nasal character of the suffix -anth was reflected in the phonologically more reduced form -et; the plural form -et still had a nasalized vowel which triggered vowel lengthening in the suffix, which in turn prevented syncope. Only after plural -et fully lost its nasal character was schwa syncope possible. The reason why plurals show much less $t$-deletion than the third person singular forms is because the necessary precondition to $t$-deletion, namely schwa syncope, occurred later in the plural than in the singular.
} 
$1 p=3 p \neq 2 p$

First and third person plural are homophonous in 65 Dutch dialects. If first and third person plural are homophonous they are always marked with $-e(n)$. Second person is either marked with $-t(53 \mathrm{x})$ as shown in (36) or with $-\varnothing(12$ times) as shown in (37).

$$
1 p=3 p \neq 2 p:-e(n) \text { versus }-t(53 \mathrm{x})
$$

\begin{tabular}{ll|}
1 & $-e(n)$ \\
2 & $-t$ \\
3 & $-e(n)$ \\
\hline
\end{tabular}

(37) $1 p=3 p \neq 2 p:-e(n)$ versus $-\varnothing(12 \mathrm{x})$

\begin{tabular}{ll}
\hline & \\
1 & $-e(n)$ \\
2 & $-\varnothing$ \\
3 & $-e(n)$ \\
\hline
\end{tabular}

The appearance of $-e(n)$ as a plural suffix marking is a form of conservatism; it is a preservation of Middle Dutch. The $-t$ as a marker for second person plural is also the result of conservatism. Zero marking for second person plural results from $-t$-deletion.

\subsection{Summary}

The existence of cross-linguistically uncommon patterning, namely the syncretism between first and third person is always the result of conservatism in the plural. As we saw in the subsection on person neutralization in the plural, many dialects were not conservative and lost this distinction via the acquisition route. The syncretism between first and third person singular in the singular can be related to - $t$-deletion and schwa-deletion that created homophony between first and third person singular. The cross-linguistically more common patterning of first and second person was not attested in the plural and only infrequently attested in the singular. The cross-linguistically more common patterning of second and third person was attested with a very high frequency in the singular: 190 dialects show this syncretism. The syncretism can be related to the pragmatic route that brought second person plural $-t$ to the 
singular; The originally second person plural suffix $-t$ is homophonous with third person singular marking.

\subsection{Neutralization of number}

In Middle Dutch we have no examples of number neutralization. As shown in (38) our 352 contemporary Dutch dialects show number neutralization in first person 10 times. There are 103 dialects that show a syncretism between the second person singular and second plural. There are 62 dialects that do not express number in third person.

(38) Number neutralization in the context of person

\begin{tabular}{|l|l|}
\hline & Singular $=$ Plural \\
\hline 1 & 10 \\
\hline 2 & $103 / 91$ \\
\hline 3 & $62 / 48$ \\
\hline
\end{tabular}

$1 s=1 p$

The distribution of first person syncretisms is limited: first person singular and first person plural share a suffix in 10 dialects in the South-western province of Zeeland. One suffix for first person singular and first person plural appears in two different forms: $-e(6 \mathrm{x})$ or $-e n(4 \mathrm{x})$. If we look at the paradigms in (39) and (40) we see that a person syncretism is never a pure person syncretism. The suffix that marks first person also marks all plural forms.

(39) $1 s=1 p$ : suffix $-e(6 \mathrm{x})$

\begin{tabular}{lll|} 
& \multicolumn{1}{c}{ Singular } & Plural \\
& & \\
\cline { 3 - 3 } 1 & $-e$ & $-e$ \\
2 & $-t /-\varnothing /-e$ & $-e$ \\
3 & $-t$ & $-e$ \\
\hline
\end{tabular}

(40) $1 s=1 p$ : suffix $-e n(4 \mathrm{x})$

\begin{tabular}{lll|} 
& Singular & Plural \\
& & \\
1 & $-e n$ & $-e n$ \\
2 & $-t$ & $-e n$ \\
3 & $-t$ & $-e n$ \\
\hline
\end{tabular}


The first person syncretism in the form of $-e$ (39) is phonologically motivated. In Middle Dutch first person singular was marked with $-e$ and first person plural was marked with -en. In most Dutch dialects two phonological rules were active: word final $-e$ was deleted in stems and later on $-n$ was deleted after schwa (compare 8). In Standard Dutch these two rules resulted in a marker $-\varnothing$ for first person singular and $-e$ for first person plural. In Zeeland many dialects preserved $-e$ in word final position (Weijnen 1941) and after the $-n$ deletion rule, $-e$ marked both first person singular and first person plural. The combination of the occurrence of $n$-deletion and the non-occurrence of schwa deletion created a first person syncretism.

The overlap between first person singular and all plural forms that characterizes the $-e$ forms also characterizes the -en forms. In Sect. 5.2 we formulated two types of evidence for the amplification route: the abstract paradigm should have a phonological motivation (i) and the distribution of the paradigm should be confined to the area where there is evidence for phonological patterning of the abstract paradigm (ii). The observation that the abstract syncretic pattern of the - $e$ forms matches the -en forms fulfills the first requirement for the amplification route. Let us now look at the geographical distribution of first person marked by $-e$ and first person marked by -en. The dialects that mark first person with -en are marked with circles in map 2, the dialects that mark first person with $-e$ are marked with a plus. In map 2 we see that -en only marks first person singular in the two areas where $-e$ still functions as a marker for first person, suggesting that the appearance of -en in the first person singular is indeed the effect of the amplification route.

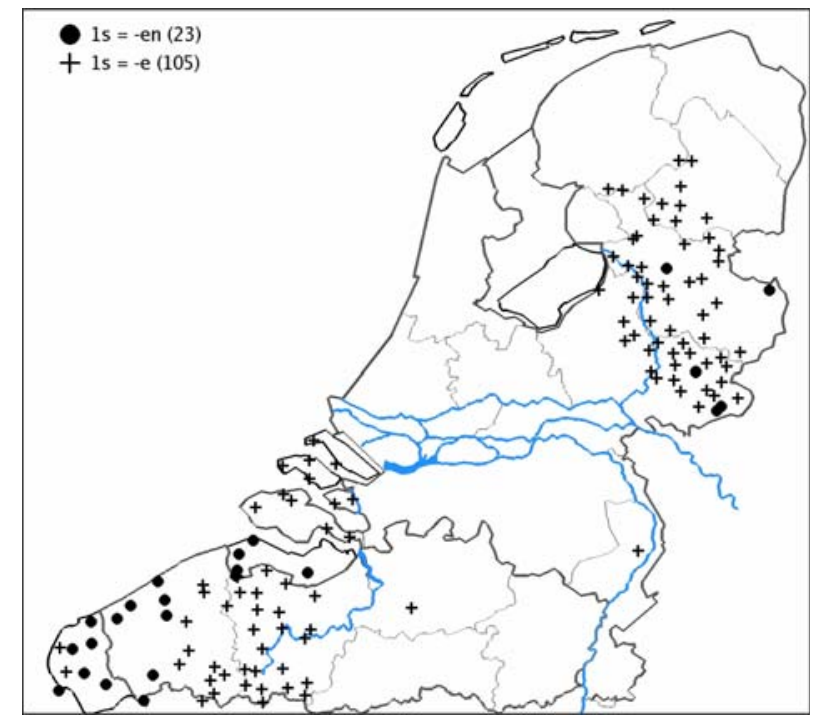

Map. 2 Distribution of $1 \mathrm{~s}=e / 1 \mathrm{~s}=e n$ 
We can understand the amplification route as the follows: in the plural, $-e$ and $-e n$ were most likely in competition for a while: $n$-deletion is a gradual process. The period of competition between -e and -en is depicted in (42)

(41) Partial syncretism between first person singular and the plural forms

\begin{tabular}{ll|l}
\hline & Singular & Plural \\
& \multicolumn{2}{c|}{} \\
1 & $-e$ & $-e /-e n$ \\
2 & $-t$ & $-e /-e n$ \\
3 & $-t$ & $-e /-e n$ \\
\hline
\end{tabular}

(42) Hypothetical: full syncretism between first person singular and all plural forms

\begin{tabular}{|c|c|c|}
\hline & Singular & Plural \\
\hline 1 & -e/en & -e/en \\
\hline 2 & $-t$ & -e/en \\
\hline 3 & $-t$ & -e/en \\
\hline
\end{tabular}

If the two forms $-e$ and $-e n$ are alternates in the plural, it is possible that the language users assume that $-e$ and $-e n$ are alternates in the full paradigm via amplification, leading to (42). If the suffix $-e$ wins the competition between the alternates $-e$ and $-e n$ this leads to the paradigm in where first person and all plurals are marked with $-e$ as is the case in (39), if -en wins the competition we get paradigm (40) where first person singular, and all plurals are marked with -en.

\section{$2 s=2 p$}

Neutralization of number features in the context of second person occurs relatively frequently. In some Eastern dialects the plural is marked by -en and $-t$ and second person singular is solely marked with $-t$ as shown in (46). If we count this partial overlap in form as syncretism, we have a 103 syncretisms between second person singular and second person plural. If we disregard these Eastern examples, we have 91 examples of syncretism between second person singular and second person plural. In two cases second person singular is linked to the marker $-\varnothing$ as shown in (44), in 23 cases to the marker -en as shown in (45), in 64 cases to the suffix $-t$ as shown in (43) and in one case the syncretism between second person singular and second person plural is linked to the alternation set $-e n /-t$ as shown in (47). The suffixes - $t$, -en and -en\&-t are conservative as second person plural forms; the suffix $-\varnothing$ is the result of $-t$-deletion. The relatedness between second person singular and second person plural can be directly related to the pragmatic route: it was a politeness strategy to use 
the second person plural forms in the singular. All paradigms with a syncretism between second person singular and second person plural have cognates of the originally second person plural pronoun gij as a second person singular form. More interesting than the observation that a language specific route created the syncretism between second person singular and second person plural is the observation that many dialects have lost this syncretism again. Out of 283 dialects that have a cognate of the originally second person plural pronoun gij as a second person singular pronoun, only 103 dialects have preserved the syncretism between second person singular and second person plural.

In (48) the full paradigm of the verb kloppen in the dialect of Wijk bij Duurstede is given. Although there is no syncretism between second person singular and second person plural in this dialect, the paradigm is added because it shows the historical relatedness between second person singular and the plural forms on the one hand and the synchronic distinctiveness from second person singular and the plurals on the other hand. The fact that second person singular shows vowel lengthening reveals its plural origin. The second person plural form, however, shows the general plural marker $-e$ and the second person singular has zero marking. The form kloop in the singular is the result of -t-deletion in the form kloopt. The second person plural form kloopt has been replaced by the general plural form kloope.

(43) Number neutralization in the context of second person: suffix $-t$ (64x)

\begin{tabular}{lll|} 
& Singular & Plural \\
& & \\
1 & $-e n /-\varnothing /-e$ & $-t /-e n$ \\
2 & $-t$ & $-t$ \\
\hline 3 & $-t / \varnothing$ & $-t /-e n$ \\
\hline
\end{tabular}

(44) Number neutralization in the context of second person: suffix $-\varnothing(2 x)$

\begin{tabular}{lll|} 
& Singular & Plural \\
& & \\
1 & $-e$ & $-\varnothing$ \\
2 & $-\varnothing$ & $-\varnothing$ \\
3 & $-\varnothing$ & $-\varnothing$ \\
\cline { 2 - 3 } & &
\end{tabular}


(45) Number neutralization in the context of second person: suffix -en (23x)

\begin{tabular}{lll|} 
& Singular & Plural \\
& & \\
1 & $-\varnothing /-e$ & $-e(n)$ \\
2 & $-e(n)$ & $-e(n)$ \\
3 & $-t$ & $-e(n)$ \\
\hline
\end{tabular}

(46) Partial number neutralization in the context of second person: suffix $-t$ / - $t$ \&-en (12x)

\begin{tabular}{ll|l}
\hline & Singular & Plural \\
& \multicolumn{1}{c|}{} & \\
1 & $-e /-\varnothing$ & $-e n \&-t$ \\
2 & $-t$ & $-e n \&-t$ \\
3 & $-t$ & $-e n \&-t$ \\
\hline
\end{tabular}

(47) Number neutralization in the context of second person: suffix - $t$ \&-en (1x)

\begin{tabular}{lll}
\hline & Singular & Plural \\
& & \\
1 & $-e /-\varnothing$ & -en \& $-t$ \\
2 & $-t \&-e n$ & $-e n \&-t$ \\
3 & $-t$ & -en \& - $t$ \\
\hline
\end{tabular}

(48) Wijk bij Duurstede: vowel lengthening in second person singular and in the plural

\begin{tabular}{lll}
\hline & Singular & Plural \\
& & \\
1 & klop & kloope \\
2 & kloop & kloope \\
3 & klop & kloope \\
\hline
\end{tabular}


$3 s=3 p$

There are 59 dialects with a syncretism between third person singular and third person plural. In 15 cases shown in (50) the overlap in form is only partial. The plurals are marked with $-e n$ and $-t$ and third person is marked with - $t$. In 41 cases both third person singular and third person plural are marked by $-t$ as shown in (49). ${ }^{8}$ In two cases third person singular and third person plural are marked with $-\varnothing$ as shown in (50). In one case third person singular and third person plural are marked with -en as shown in (51).

(49) Number neutralization in the context of third person: suffix - $t$ (41x)

\begin{tabular}{lll|} 
& Singular & Plural \\
& & \\
1 & $-e n /-\varnothing /-e$ & $-t$ \\
2 & $-t$ & $-t$ \\
3 & $-t$ & $-t$ \\
\cline { 3 - 3 } & &
\end{tabular}

(50) Partial number neutralization in the context of third person: suffix- $\varnothing(2 x)$

\begin{tabular}{lll|} 
& Singular & Plural \\
& & \\
1 & $-e$ & $-\varnothing$ \\
2 & $-\varnothing$ & $-\varnothing$ \\
3 & $-\varnothing$ & $-\varnothing$ \\
\cline { 2 - 3 }
\end{tabular}

(51) Number neutralization in the context of third person: suffix -en (1x)

\begin{tabular}{lll|}
\hline & Singular & Plural \\
& & \\
1 & $-e$ & $-e n$ \\
2 & $-e n$ & $-e n$ \\
3 & $-e n$ & $-e n$ \\
\cline { 2 - 3 } & & \\
\hline
\end{tabular}

\footnotetext{
${ }^{8}$ There are 15 dialects which show alternation between -en and $-t$ marking in the plural. Two of these dialects have -st as a second person singular marking, and one dialect has -en/-t alternation in second person singular. All dialects mark third person with $-t$. The amount of partial overlap with plural forms is therefore larger in third person than in second person.
} 
(52) Partial number neutralization in the context of third person: suffix -en \& $-t(15 x)$

\begin{tabular}{lll}
\hline & Singular & Plural \\
& & \\
1 & $-e /-\varnothing$ & en \& $-t$ \\
2 & $-t /-t \&-e n$ & en \& $t$ \\
3 & $-t$ & -en \& $-t$ \\
\hline
\end{tabular}

The suffix $-t$ as a marker for third person singular and third person plural never implies only the neutralization of number. The overlap occurs only if all plurals are marked with $-t$. The syncretism between third person singular and third person plural only occurs in the Eastern dialects, and it is thus a form of conservatism. The appearance of $-\varnothing$ can be explained as the result of - $t$-deletion. The appearance of -en as a marker for third person singular can be related to amplification as shown in the discussion on the syncretisms between second and third person singular.

\subsection{Summary}

Number neutralization in the context of first or third person is never purely neutralization of number: number neutralization is always combined with person neutralization in the plural. Moreover, number neutralization is always related to language specific routes to syncretism. The most frequent context for number neutralization in the context of person in Dutch dialects is second person. There are 103 dialects that show this type of number syncretism, which is often motivated by the pragmatic route to syncretism. More interesting than the observation that a language specific route created the syncretism between second person singular and second person plural is the observation that many dialects have lost this language specific syncretism again. Out of 283 dialects that have a cognate of the originally plural pronoun gij as a second person singular pronoun, only 103 dialects have preserved the syncretism between second person singular and second person plural. In a sense we could say that the creation of a syncretism between second person singular and second person plural via a language specific route obscured feature structure. But at the same time the loss of this language specific syncretism in favour of a crosslinguistically frequent pattern reveals the strength of that same feature structure.

\section{Discussion and conclusion}

The Dutch dialect data on verbal inflection corroborate the conclusion in Baerman (2004) and Baerman et al. (2005) that there are both language 
specific and universal sources for syncretism. Accidental homophony created via phonological rules can be extended systematically via the amplification route. In our Dutch data we saw three examples of amplification. The first example of amplification is the appearance of $-t$ as a marker for all singular forms confined to the region of South Holland where $-\varnothing$ and $-t$ appear in complementary distribution. The second example of amplification is the appearance of -en as a marker for third person singular. The geographical distribution of this pattern is confined to the Eastern part of the Netherlands where the suffixes -en and $-t$ have been alternates in the marking of the plural for more than 700 years. The third form of amplification is the appearance of -en as a suffix for first person confined to those areas where first person is marked by schwa and where the plural can be marked both by schwa and by the suffix -en. Language specific routes to syncretism can thus overrule feature structure and the deviations from feature structure can be systematically codified in the language.

From the observation that deviations from feature structure can be systematically codified in a language. Baerman (2004: 62) and Baerman et al. (2005: 170) conclude that the crucial question is whether there is any constraint on the production of unnatural syncretisms. The question is what type of evidence could prove that a certain syncretism is impossible. If we find that a certain syncretism does not occur in any language, this absence of occurrence does not necessarily imply that the occurrence of that syncretism is impossible. It merely implies that no diachronic route led to that particular syncretism (cf. Anderson 2004: 14). Interaction between language specific routes to syncretism and feature hierarchy can shed more light on the issue of constraints on the formation of syncretism than the absence of a certain syncretic pattern can. One possible form of interaction between language specific routes to syncretism and feature structure is that feature structure resists a language specific path to deflection. It is imaginable that a process like deletion does not take place in certain inflectional contexts. Another thinkable form of interaction between language specific paths to deflection and feature hierarchy is the reorganization of semantic classes. Say that in a language the formal distinction between plurals and singulars is lost and that the dual remains distinctively marked. It is then possible that the meaning of the inflectional marker that is linked to the dual gets reinterpreted as a plural marker. If such reinterpretation took place, this would constitute evidence for the dependency relation between the marked category dual and the more general category plural. In the Dutch dialect data we saw another form of interaction between language specific routes to syncretism and feature structure. The language specific route created a syncretism between second person singular and second person plural. Feature structure destroyed this syncretism in two thirds of the Dutch dialects in favour of a cross-linguistic common systematic distinction between singular and plural forms. The pervasive loss of the language specific pattern shows the power of feature structure.

In Sect. 5 we saw that in 190 Dutch dialects there is a syncretism between second and third person singular. We related this cross-linguistically common 
pattern to the pragmatic route to syncretism. The picture, however, could be more interesting. Although almost all European languages used a second person plural form as a singular polite form of address, there are only two European languages that have lost their second person singular: English and Dutch. In Aalberse (2004) I relate the unique position of English and Dutch to feature structure. The fact that loss of the second person singular created a cross-linguistically common collapse between first and second person singular in English and between second and third person in Dutch gave a boost to the pragmatic route. The claim is that without feature structure, second person singular would not have been fully lost. A similar claim that pronoun loss is partly related to verbal deflection is made for the loss of first person plural nous in French by Coveney (2000) and for the loss of second person singular tu and first person plural nos in Brazilian Portuguese by Zilles (2005).

The benefit of the study of the interaction between language specific routes to syncretism and feature structure is threefold. We know language specific routes to syncretism can obscure feature structure. By distinguishing the different routes to syncretism, we can also reveal the strength of feature structure. Secondly, distinguishing sources of syncretisms enables us to understand similarities and differences in the cross-linguistic patterning of syncretisms. Moreover, we can link typological data to language acquisition patterns. The function of feature structure in language acquisition is the anticipation of typologically frequent syncretic patterns by language learners. We predict that feature-structure-driven syncretic patterns are acquired early and even produced if they are not target-like. The language learner on the other hand cannot anticipate language specific patterning, and we therefore predict that language specific syncretisms are more prone to errors (cf. Pinker 1996: 178-179, 183).

Cysouw (2005: 250) writes that an optimality approach could describe the data on syncretisms well, but he fears there is no external rationale for constraints in the domain of syncretisms. The distinction between feature-structuredriven syncretisms and non-feature-structure driven syncretisms can provide theoretical body to optimality-like constraints. In the Dutch case the pragmatic route to syncretism provided a constraint that required the non-expression of number in the context of second person. Feature-structure provided the constraint of the non-expression of person in the plural. The two constraints were in competition for a while, and in most dialects the feature-structure-driven constraint won: person is not marked in the plural in most Dutch dialects. Unlike more standard optimality-like constraints, non-feature-structure-driven sources for syncretism and feature-driven sources for syncretism are not only in competition with each other, they can also boost each other. An example of a boosting relationship between syncretism sources is the loss of person marking in the singular: Loss of person marking in the singular is motivated both by feature structure and by the -t-deletion rule. It is the dynamic interaction between feature-structure-driven motivation for syncretisms and language specific sources of syncretism that can reveal more about the organization of feature structure and on the possible constraints on the formation of 
syncretisms. In order to find out more about this interaction, we need typological information combined with information on the acquisition of inflectional markers and knowledge of language specific sources of syncretism.

Acknowledgements I am grateful to the audience of the conference Variation in Inflection in Amsterdam (December 2005) for discussion of the oral presentation of this paper. I would also like to thank two anonymous reviewers, Ingo Plag from the editor team, Elma Blom, Fred Weerman, Hans Bennis, Peter Ackema and Horst Simon for detailed and very useful comments on earlier drafts. Jan Don and Alies Maclean were always there for walk-in discussion of the data. I am indebted Gunther de Vogelaer and especially to Ton Goeman for inspiring e-mails. I hope I have done justice to their vast knowledge of dialectal variation and diachronic developments in Dutch.

\section{References}

Aalberse, S. (2004). Waer bestu bleven? De verdwijning van het pronomen 'du' in een taalvergelijkend perspectief. Nederlandse Taalkunde, 9(3), 231-254.

Ackema, P., \& Neeleman, Ad. (2004). Beyond morphology. Interface conditions on word formation. Oxford: Oxford University Press.

Aikhenvald, A. Y., \& Dixon, R. M. (1998). Dependencies between grammatical systems. Language, 74(1), 56-80.

Anderson, S. R. (2004). Morphological universals and diachrony. In G. E. Booij, \& J. van Marle (Eds.), Yearbook of morphology (pp. 1-14). Dordrecht: Springer.

Baerman, M. (2004). Typology and the formal modelling of syncretism. In G. E. Booij, \& J. van Marle (Eds.), Yearbook of morphology (pp. 41-72). Dordrecht: Springer.

Baerman, M. (2005). Directionality and (Un)natural classes in syncretism. Language, 80(4), $807-824$.

Baerman, M., \& Brown, D. (2005a). Syncretism in verbal person/ number marking. In M. Haspelmath, \& H. J. Bibiko (Eds.), The World Atlas of language structures (pp. 122-123). Oxford: Oxford University Press.

Baerman, M., \& Brown, D. (2005b). Case syncretism. In M. Haspelmath, \& H. J. Bibiko (Eds.), The World Atlas of language structures (pp. 118-119). Oxford: Oxford University Press.

Baerman, M., Brown, D., \& Corbett, G. G. (2005). The syntax-morphology interface. A study of syncretism. Cambridge: Cambridge University Press.

Barbiers, S., et al. (2006). 2006 Dynamische Syntactische Atlas van de Nederlandse Dialecten (DynaSAND) <http://www.meertens.nl/sand/> Accessed on March 1st 2007.

Bennis, H., \& MacLean, A. (2007). Variation in verbal inflection in Dutch dialects. Morphology, 16(2).

Brown, P. and Levinson, S. C. (1987). Politeness Some universals in language usage. Cambridge: Cambridge University Press.

Buitenrust-Hettema, F. (1891). De aangesproken persoon. Taal en Letteren, 1, 148-153.

Bybee, J. L. (1985). Morphology: A study of the relation between meaning and form. Amsterdam: John Benjamins.

Comrie, B. (1975). Polite plurals and predicate agreement. Language, 51(2), 406-418.

Coveney, A. (2000). Vestiges of Nous and the 1st person plural verb in informal spoken French. Language Sciences, 22(4), 447-481.

Cysouw, M. (2003). The paradigmatic structure of person marking. Oxford: Oxford University Press.

Cysouw, M. (2005). What it means to be rare: The variability of person marking. In: Z. Frajzyngier, A. Hodges, \& D. S. Rood (Eds.), Linguistic diversity and language theories (pp. 235258). Amsterdam, Philadelphia: Benjamins.

De Vogelaer, G. (2005). Subjectsmarkering in de Nederlandse en Friese dialecten. <http://users.ugent.be/ gdvogela/proefschrift>. Accessed on January 22nd 2007.

Evans, N., Brown, D., \& Corbett, G. (2000). Dalabon pronominal prefixes and the typology of syncretism: A network morphology analysis. Yearbook of Morphology. 
Franck, J. (1910). Mittelniederländische Grammatik mit Lesestücken und Glossar. Leipzig: Tauchnitz.

Goeman, A. C. M., \& Taeldeman, J. (1996). Fonologie en morfologie van de Nederlandse dialecten. Een nieuwe materiaalverzameling en twee nieuwe atlasprojecten. Taal en Tongval, 48, $38-59$.

Goeman, A. C. M. (1999). T-deletie in Nederlandse dialecten. Kwantitatieve analyse van structurele, ruimtelijke en temporele variatie. Den Haag: Holland Academic Graphics.

Harley, H. (1994). Hug a tree: Deriving the morphosyntactic feature hierarchy. MIT Working Papers in Linguistics, 21, 289-320.

Harley, H., \& Ritter, E. (2002). Person and number in pronouns: A feature-geometric analysis. Language, 78(3), 482-526.

Head, B. (1978). Respect degrees in pronominal reference. In J. H. Greenberg (Ed.), Universals of human language (pp. 151-211). Stanford: Stanford University Press.

Heath, J. (1991). Pragmatic disguise in pronominal-affix paradigms. In F. Planck (Ed.), Paradigms: The economy of inflection (pp. 75-90). Berlin: Mouton de Gruyter.

Heath, J. (1998). Pragmatic skewing in 1-2 pronominal combinations in native american languages. International Journal of American Linguistics, 64(2), 83-104.

Hickey, R. (2003). Rectifying a standard deficiency. Second-person pronominal distrinctions in varieties of English. In I. Taavitsainen, \& A. H. Jucker (Eds.), Diachronic perspectives on address term systems (pp. 343-373). Amsterdam, Philadelphia: John Benjamins.

Lass, R. (1999). Phonology and morphology. In R. Lass (Ed.), The Cambridge history of the English language. 1476-1776 (vol. III pp. 56-186). Cambridge: Cambridge University Press.

Maiden, M. (1992). Irregularity as a determinant of morphological change. Journal of Linguistics, 28(2), 285-312.

Pinker, S. (1996). Language learnability and language development. Cambridge, MA: Harvard University Press.

Van Aken, H. (1996). Van uitgang tot vooruitgang: het verdwijnen van de werkwoordsuitgangen van de tweede persoon uit het Nederlands. Utrecht: manuscript.

Van den Berg, B. L. (2003). Phonology \& morphology of Dutch \& Frisian Dialects in 1.1 million transcriptions. Goeman-Taeldeman-Van Reenen project 1980-1995, Amsterdam: Meertens Instituut. (CD-ROM). Amsterdam: Meertens Instituut.

Van Gestel, F., Nijen, T. J., Rinkel, T., \& Weerman, F. (1992). Oude zinnen. Grammaticale analyse van het Nederlands tussen 1200-1700. Leiden: Martinus Nijhoff.

Vermaas, H. (2002). Veranderingen in de Nederlandse aanspreekvormen van de dertiende $t / m$ de twintigste eeuw. Utrecht: LOT.

Vor der Hake, J. A. (1908). De aanspreekvormen in 't Nederlandsch. Utrecht: P. Den Boer.

Wales, K. (2004). Second person pronouns in contemporary English: The end of a story or just the beginning? Franco British Studies, 33-34, 172-185.

Watkins, L. J. (1984). A grammar of Kiowa. Lincoln: University of Nebraska Press.

Weerman, F., \& De Wit, P. (1999). The decline of the genitive in Dutch. Linguistics, 37(6), 1155-1192.

Weijnen, A. (1941). De Nederlandse dialecten. Groningen: Noordhoff.

Zilles, A. M. S. (2005). The development of a new pronoun: The linguistic and social embedding of a gente in Brazilian Portuguese. Language Variation and Change, 17(1), 19-53. 